\title{
Hardened cement paste microstructure as the main factor of concrete durability
}

\author{
Kirill Shuldyakov ${ }^{1, *}$, Alena Kirsanova ${ }^{1}$, Lyudmila Kramar $^{1}$, and Boris Trofimov ${ }^{1}$ \\ ${ }^{1}$ South Ural State University, 454080 Chelyabinsk, Russia
}

\begin{abstract}
When studying durability of concrete the main emphasis is put on its resistance to frost, water and sulphate, which depends on type, dispersion and stability of cement hydration products. The paper focuses on interrelation between strength, open porosity and peculiarities of microstructure of hydrated phases and their crystallization tendency under cyclic and chemical actions. In order to find out these dependences, the following parameters were defined in compliance with standards: open porosity of concrete by water absorption, compressive and tensile strength in bending, frost resistance and sulphate resistance. Methods applied in the research are X-ray diffraction analysis and scanning electron microscopy. The most promising structure of hardened cement paste for obtaining modern paving concrete is the one formed by weakly crystallized gel phases of type C-S-H(I) which are resistant to crystallization and provide stability and durability of concrete. One of the most used methods to obtain such structure is addition of compounds containing activated pozzolanic materials and superplasticizers.
\end{abstract}

\section{Introduction}

Modern construction requires the use of durable and high-performance concretes with set performance properties [1-4]. Such concretes are used in construction of unique buildings, underground structures and are particularly demanded today in road construction. In practice, modern prefabricated and cast-in-place road and airfield pavements are not always durable for various reasons [1, 4-5].

Among the factors affecting their durability are, first of all, the used materials; they shall be of high quality and meet the required standards [3-4, 6-7].

Resistance of cement concretes to the operating environment is primarily dependent on the water-cement ratio, cement hydration degree and phase composition of hardened cement paste [2, 8, 9]. Water-cement ratio for high-performance concretes does not normally exceed 0.35 , which is reached by using superplasticizers [3, 10]. However, decrease of water-cement ratio does not completely solve the issue of durability. Durable concrete can be obtained by adding modifying admixtures - highly reactive silica and others $[11,12]$. When using pozzolanic admixtures cement hydration is activated, and hardened cement paste is preferably formed from low-basic amorphized calcium silicate hydrates. Such structure has low porosity and is resistant to crystallization, which considerably

\footnotetext{
* Corresponding author: kirill-shuld@ya.ru
} 
improves strength of hardened cement paste in aggressive environments [3, 8, 13]. Consequently, concrete durability can be provided by managing its content, amount of hydrate formations and porosity.

According to the regulatory documents on road construction, concrete durability is defined by its resistance to water, frost and its capability to resist the action of aggressive environments $[2,14]$. Such durability evaluation is carried out on the basis of secondary indications, without the account of structural characteristics of concrete hardened cement paste, which is a relevant issue according to many researchers $[7,15,16]$.

This research is aimed at studying the influence of phase composition in hardened cement paste modified by various admixtures on microstructure and durability of concrete.

\section{Materials and Methods}

The following materials were used during the study:

- cement of brand CEM I 42..5 N, NG (ЦЕM I 42,5 H, НГ) 28\% standard consistency corresponding to GOST 31108-2016;

- fine-grained filler - coarse sand, with the fineness modulus $=2.73$ according to GOST 8736-2014;

- coarse-grained filler - granodiorite crushed stone, size 5-20 mm, brand with regard to strength - 1400 , with regard to abrasion capacity - I1, frost resistance corresponds to the brand F400 according GOST 8267-93;

- superplasticizers: on the basis of polycarboxylate - Glenium ACE 430 (ACE), BASF, produced in Germany; on the basis of naphthalene-formaldehyde - SP-1, produced in Pervouralsk town, Russia;

- granulated silica fume (SF) with pozzolan activity of $1575 \mathrm{mg} / \mathrm{g}$ and $\mathrm{S}_{\mathrm{sp}}=1500$ $\mathrm{m}^{2} / \mathrm{kg}$, produced in Novokuznetsk city, Russia (TU 5743-048-02495332-96).

Specimens with the size of $10 \times 10 \times 10 \mathrm{~cm}$ and the same water-cement ratio $=0.33$ were produced according to GOST 10180-2012 to define strength properties of concrete, its porosity and frost resistance [17]. Frost resistance was evaluated in compliance with GOST 10060-2012 by using the quick method No. 3 [18]. Sulphate resistance of hardened cement paste was defined according to GOST P 56687-2015 [19]. Concrete porosity was determined by water absorption according to GOST 12730.3-78 [20].

Phase composition of hardened cement paste in concrete was studied using X-ray diffraction analysis on the apparatus DRON-3M with PDWin attachment, as well as scanning electron microscopy using JSM-6460LA device.

\section{Results}

To conduct the research 5 series of samples were prepared - a reference one, without admixtures; those modified by plasticizers ACE and SP-1; and those with compound admixtures $\mathrm{ACE}+\mathrm{SF}$ and $\mathrm{SP}-1+\mathrm{SF}$.

Preliminary research was conducted on open porosity and strength of concretes with various admixtures. The results of studying water adsorption in concrete samples by weight $\left(\mathrm{W}_{\mathrm{w}}, \%\right)$ are given in Figure 1. According to the obtained data the highest open porosity which is directly related to water adsorption is observed in plain concrete samples. When adding only plastisizers the water absorption decreases from $6 \%$ to $4.2 \%$ and $3.8 \%$ for SP-1 and ACE respectively, which means performance of polycarboxylate plasticizer is higher than that of naphthalene-formaldehyde one. When compound admixture of ACE+ SF is used water adsorption decreases up to $3.2 \%$. 


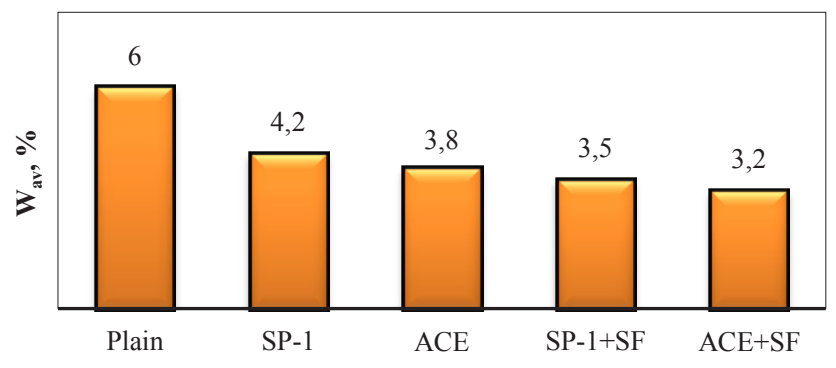

Fig. 1. Influence of admixtures on water adsorption of concrete.

Open porosity is interrelated with strength of concrete, the result of strength parameters variation is presented in Figures 2 and 3.

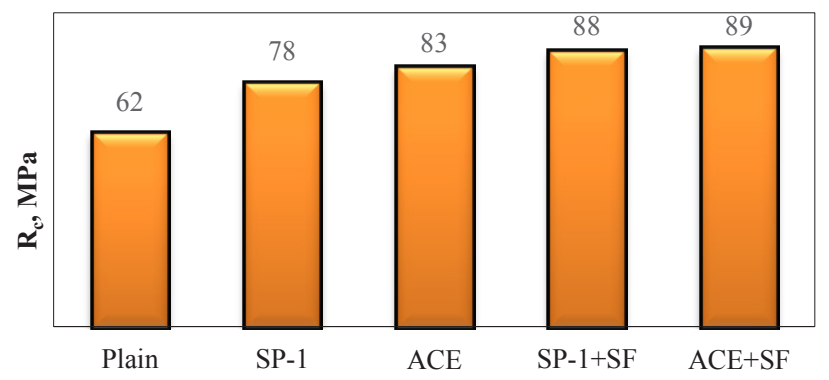

Fig. 2. Influence of admixtures on compressive strength $\left(\mathrm{R}_{\mathrm{c}}\right)$.

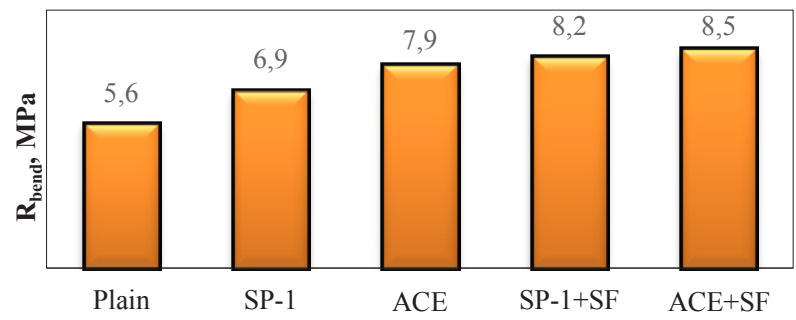

Fig. 3. Variation of tensile strength of concrete with admixtures in bending $\left(\mathrm{R}_{\text {bend }}\right)$.

The results of testing compressive strength and tensile strength in bending confirm the previously developed dependences for water adsorption and demonstrate that the highest values of the studied parameters are found in compositions modified by compound admixtures of SP-1+SF and $\mathrm{ACE}+\mathrm{SF}$. When comparing concretes with plasticizer modification only, concrete with ACE admixture demonstrates better mechanical properties, it is particularly visible for strength in bending with adding compound admixtures.

According to X-ray diffraction analysis, phase composition of hardened cement paste without admixtures and with plasticizers is preferably formed from high-basic hydrosilicate phases of type C-S-H(II) and has strong tendency to crystallization. This is confirmed by the data of scanning electron microscopy presented in Figure 4. 


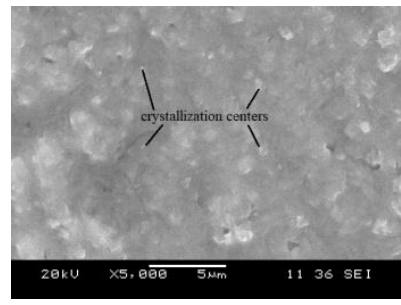

a)

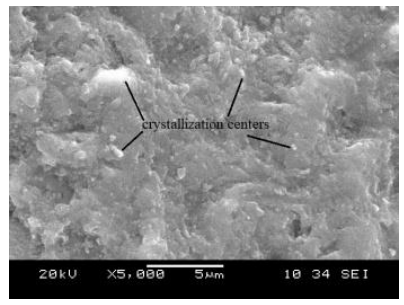

b)

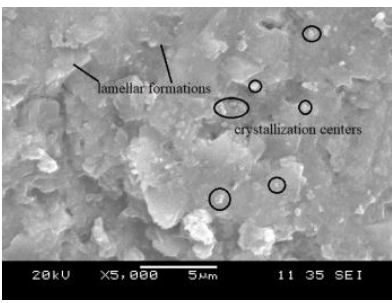

c)

Fig. 4. Microstructure of hardened cement paste: a) plain; b) with SP-1 admixture; c) with ACE admixture.

Hardened cement paste of plain concrete and concrete with SP-1 admixture has considerable amount of crystallization centers of hydroxide and calcium silicate hydrate all over the surface of the sample. Introduction of ACE admixture results in decrease of crystallization centers in the sample and increase of the number of laminate formations from high-basic phases.

According to the data of -ray diffraction analysis hardened cement paste with compound admixtures that include SF and SP-1 and ACE superplasticisers has higher content of hydrosilicate phases of type C-S-H(I). As can be seen in Figure 5, these phases form the structure from hydrosilicates of laminate type.

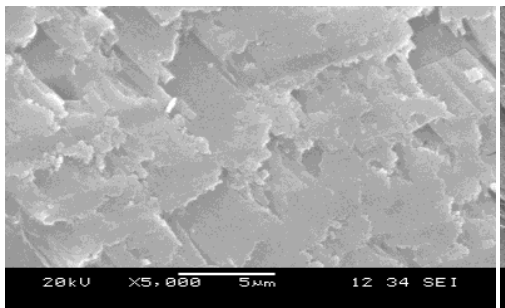

a) $\mathrm{SP}-1+\mathrm{SF}$

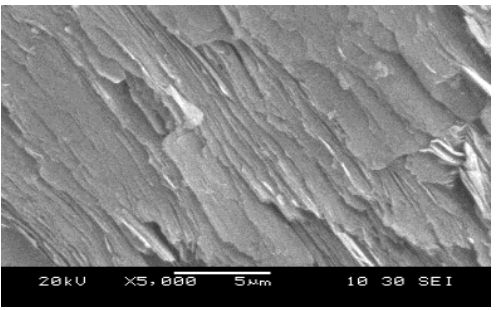

b) ACE+ SF

Fig. 5. Microstructure of hardened cement paste with compound admixtures.

Plates fit tight against each other, thus forming closed self-protecting structure resistant to moist and crystallization; such structure has improved compressive properties and particularly higher bending properties, which provides high durability of concrete. A part of crystallized calcium hydroxide is located between the plates, it is not subjected to leaching for a long time and causes no environmental $\mathrm{pH}$ variation under cyclic actions. Liquid phase stability in hardened cement paste under any external actions leads to slowdown of crystallization processes in calcium silicate hydrate.

When exploiting the roads in local conditions including the effects of low temperatures, anti-icing agents, aggressive ground waters, exhaust fumes and others, investigation of concrete's resistance to frost and sulphate is required. In this connection, durability of concrete was studied in this research with regard to its frost and sulphate resistance, the results are presented below. From Figure 6 it is seen that frost resistance of plain concrete corresponds to the maximum of brand $\mathrm{F}_{2} 100$. 


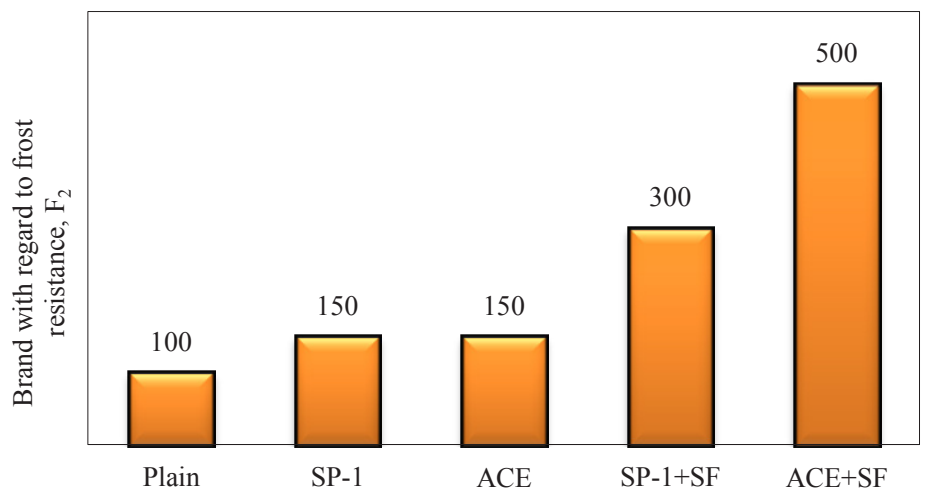

Fig. 6. Influence of admixtures on frost resistance of concrete.

Concretes with plasticizer admixtures sustained a higher, but still quite low number of cycles and thus were related to the brand $\mathrm{F}_{2} 150$. Whereas frost resistance of plain concrete and concrete with plasticizer admixtures has little difference, in concretes with silica fume admixture it increases up to $\mathrm{F}_{2} 300$ for $\mathrm{SP}-1+\mathrm{SF}$ and up to $\mathrm{F}_{2} 500$ for $\mathrm{ACE}+\mathrm{SF}$. To better understand the processes occurring in the structure of concrete hardened cement paste scanning electron microscope investigations were carried out, the results thereof are given in Figure 7.

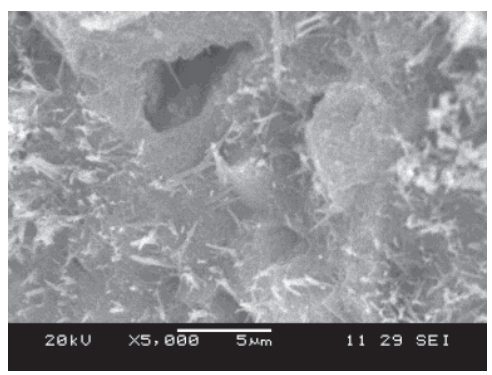

a) $\mathrm{SP}-1+\mathrm{SF}$

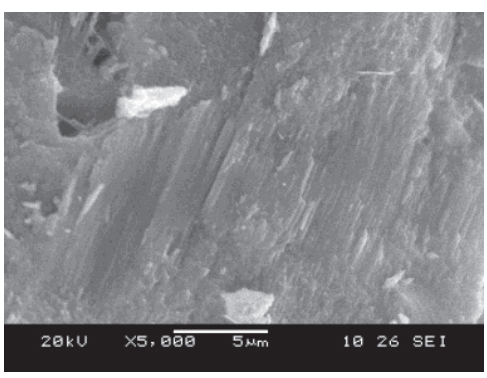

b) $\mathrm{ACE}+\mathrm{SF}$

Fig. 7. Concrete hardened cement paste with a compound admixture after 55 freeze-thaw cycles.

Based on the obtained data supported by the X-ray diffraction analysis results, one can conclude that the structure of hardened cement paste of concrete with addition of ACE+SF is represented by low-basic amorphized calcium silicate hydrates of laminate structure and can sustain long-term cyclic actions without changing. Hardened cement paste of concrete with SP-1+SF admixtures has higher tendency to crystallization, which has negative effect on its performance properties.

The data of sulphate resistance tests confirmed higher properties of concretes with $\mathrm{ACE}+\mathrm{SF}$ and SP-1+SF, which is demonstrated in Figure 8. 


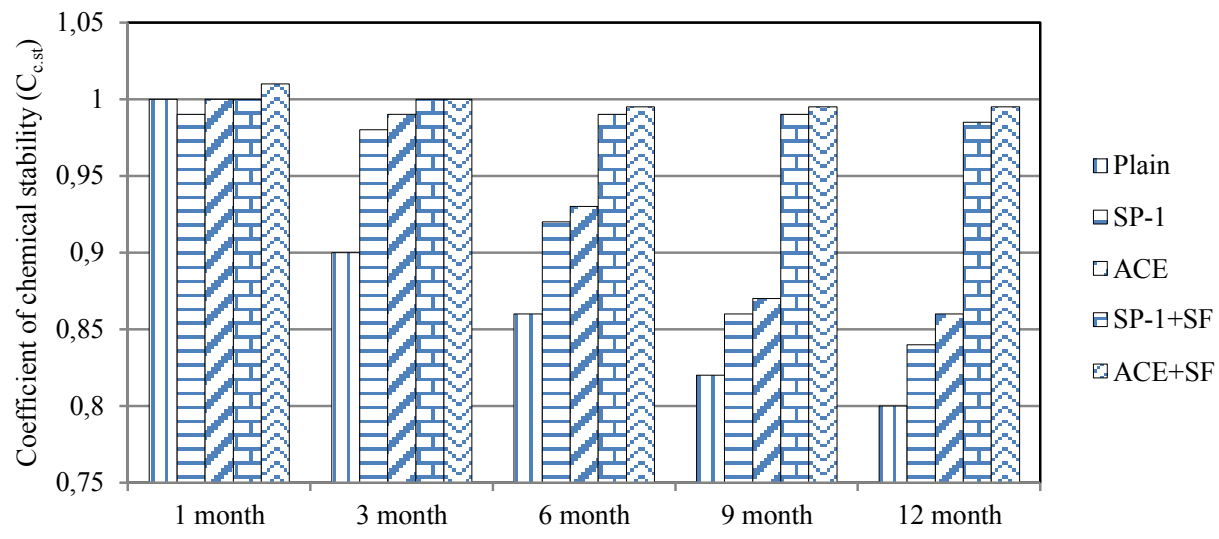

Fig. 8. Results of sulphate resistance tests of the studied concretes.

The obtained results demonstrate that practically all compositions aged 1 month have coefficients of chemical stability close to 1 . First variations are observed at the age of 3 months, when strength of the reference composition drops significantly, which causes variation of $\mathrm{C}_{\mathrm{c} . \mathrm{st} \text {. }}$ from 1 to 0.9 and the composition loses its resistance to sulphates. At the age of 6 months compositions with plasticizers have the value of $\mathrm{C}_{\text {c.st. }}=0.92$ and 0.93 for SP-1 and ACE respectively. By the age of 9 months the value of $\mathrm{C}_{\text {c.st. }}$ for concretes with plazticizers drops below the acceptable value of 0.9 ; whereas concretes modified by the compound of $\mathrm{ACE}+\mathrm{SF}$ and $\mathrm{SP}-1+\mathrm{SF}$ preserve their value of $\mathrm{C}_{\text {c.st. }}$ close to 1 even at the age of 12 months. In that manner, the use of compounds of ACE $+\mathrm{SF}$ and SP-1+SF allows obtaining sulphate resistant concretes.

\section{Conclusion}

The most efficient means to increase strength and durability of high-performance concrete is the use of compound admixtures that modify the structure of hardened cement paste for obtaining durable road pavement. Use of only polycarboxylate superplasticizer as admixture causes formation of structure represented by high-basic calcium silicate hydrate which is irresistible to cyclic actions.

Compound admixture Glenium ACE 430+SF provides formation of dense structure from low-basic weakly crystallized hydrosilicate new formations of type C-S-H(I), such structure is resistant to recrystallization when freezing and thawing and has higher bend strength in sulphate attack. Further investigation of the influence of structure and phase composition of hardened cement paste on road concrete's resistance to cyclic mechanical actions are required.

The work was supported by Act 211 Government of the Russian Federation, contract № 02.A03.21.0011.

\section{References}

1. V.F. Stepanova, Dolgovechnost' $i$ zashhita konstrukcij ot korrozii [Durability and protection of structures against corrosion], 32-37 (Moscow, 1999) (in Russian) 
2. Ju.M. Bazhenov, Tehnologija betona [Concrete technology], 528 (ACB Publ., Moscow, 2011) (in Russian)

3. P.-C. Aitcin, High-Performance Concrete, 591 (E\&FN Spon an imprint of Routledge, London and New York, 1998)

4. S. Caijun, W. Zemei, X. Jianfan, W. Dehui, H. Zhengyu, F. Zhi, Construction and Building Materials, 101, part 1, 741-751 (2015)

5. W. Dehui, S. Caijun, W. Zemei, X. Jianfan, H. Zhengyu, F. Zhi, Construction and Building Materials, 96, 368-377 (2015)

6. T.C. Powers, T.L. Brownyard, JACI, 77(4), 264-268 (1980)

7. S.V. Shestopjorov, Dolgovechnost' betona transportnyh sooruzhenij [Durability of transport infrastructure facilities from concrete], 500 (Transport, Moscow, 1998) (in Russian)

8. L.Ya. Kramar, B.Ya. Trofimov, K.V. Shuldyakov, Civil Engineering and Ecology: Theory, Practice, Innovation, Proceedings of the I International Scientific Conference, 168-175 (Chelyabinsk, March 9, 2015) (in Russian)

9. I.M. Ivanov, D.V. Matveev, A.A. Orlov, L.Ya. Kramar, Bulletin of the South Ural State University, 17(2), 42-49 (2017) (in Russian)

10. Z. Yanrong, K. Xiangming, Cement and Concrete Research, 69, 1-9 (2014)

11. L.Ya. Kramar, B.Ya. Trofimov, E.A. Gamaliy, T.N. Chernykh, V.V. Zimich, Modifikatory cementnyh betonov (Tehnicheskie harakteristiki i mehanizm dejstvija), 202 (Iskra-Profi, Chelyabinsk, 2012) (in Russian)

12. V.S. Izotov, Himicheskie dobavki dlja modifikacii betona [Chemical additives for concrete modification], 109 (Paleotip, Moscow, 2006) (in Russian)

13. A. Traetteberg, Cemento, 3, 369-375 (1978)

14. S.W. Tang, Y. Yao, C. Andrade, Z.J. Li, Cement and Concrete Research, 78, part A, 143-154 (2015)

15. B.Ya. Trofimov, L.Ya. Kramar, Stroitel'nye materialy [Building materials], 8, 46-51 (2014) (in Russian)

16. H. Huang, C. Qian, F. Zhao, J. Qu, J. Guo, M. Danzinger, Construction and Building Materials, 110, 293-299 (2016)

17. GOST 10180-2012 Concretes. Methods for strength determination using reference specimens (Moscow, 2012) (in Russian)

18. GOST 10060-2012 Concretes. Methods for determination of frost-resistance (Moscow, 2012) (in Russian)

19. GOST P 56687-2015 Protection of concrete and reinforced-concrete constructions from corrosion. Test method of sulfate resistance of concrete (Standartinform Publ., Moscow, 2015) (in Russian)

20. GOST 12730.3-78 Concretes. Method of determination of water absorption (Moscow, 2007) (in Russian) 